\title{
DESA WISATA EDUKASI MENUJU WISATA RAKYAT BERKELANJUTAN DI KABUPATEN SITUBONDO (WISATA EDUKASI HIDROPONIK OLEAN)
}

\section{EDUCATIONAL TOURISM VILLAGE TOWARDS SUSTAINABLE COMMUNITY TOURISM IN SITUBONDO (OLEAN HYDROPONIC EDUCATIONAL TOURISM)}

\author{
Yudhistira Harisandi ${ }^{1}$, Muhammad Iqbal Anshory ${ }^{2}$ \\ ${ }^{1}$ Manajemen, Fakultas Ekonomi, Universitas Abdurachman Saleh Situbondo \\ ${ }^{2}$ Manajemen, Fakultas Ekonomi, Universitas Abdurachman Saleh Situbondo \\ Yudhistira.yt94@gmail.com
}

\begin{abstract}
Abstrak: Desa Olean, Kecamatan Situbondo, Kabupaten Situbondo memiliki banyak potensi wisata yang baik. Tetapi perkembangan Desa Olean sebagai daya tarik wisata mengalami pasang surut. Desa Olean adalah Desa wisata yang belum banyak dikenal oleh masyarakat Kota Situbondo. Untungnya masyarakat Desa Olean cepat tanggap untuk mengelola dan meningkatkan sumber daya yang ada untuk mengangkat nama desa mereka. Untuk memberikan alternatif wisata yang lebih beragam lagi di bidang tanaman, maka Olean merencanakan mengembangkan diri sebagai Desa Wisata Edukasi, sehingga menjadi daya tarik wisata adalah seluruh desa beserta sistem kehidupannya. Desa wisata menawarkan pengalaman baru yaitu kehidupan alam pedesaan, udara segar, dan kehidupan yang jauh dari polusi dan kebisingan, dan keterlibatan dalam aktivitas masyarakat setempat dalam artian bahwa wisatawan tidak hanya melihat begitu saja keindahan alam, tetapi dapat hidup di dalamnya. Wisatawan dapat merasakan dan menikmati secara utuh alam dan sosial budaya di yang sudah dibuat oleh desa tersebut. Terkat hal tersebut, tujuan dari kegiatan pengabdian ini adalah (1) Pengembangan wisata edukasi yang berbasis masyarakat dan berkelanjutan, (2) Memberikan manfaat kepada masyarakat, yaitu dapat meningkatkan pendapan masyarakat, (3) Menjaga kelestarian Desa Olean dan untuk menghindari alih fungsi lahan yang tidak terkendali
\end{abstract}

Kata Kunci: PKM, Desa Wisata Edukasi, Desa Olean, Hidroponik

\begin{abstract}
Olean Village, Situbondo District, Situbondo Regency has a lot of good tourism potentials. However, the development of Olean Village as a tourist attraction experiences ups and downs. Olean Village is a tourist village that is not yet well known by the people of the city of Situbondo. Fortunately the people of Olean Village are responsive to managing and increasing available resources to raise the name of their village. To provide a more diverse alternative tourism in the field of plants, Olean plans to develop itself as an Educational Tourism Village, so that the tourist attraction is the entire village and its life system.
\end{abstract}




\section{INTEGRITAS : Jurnal Pengabdian}

Vol 3, No 2, Desember 2019

ISSN 2580-7978 (Cetak) ISSN 2615-0794 (Online)

The tourism village offers a new experience of rural natural life, fresh air and life away from pollution and noise, and involvement in the activities of the local community in the sense that tourists not only see the natural beauty, but can live in it. Tourists can feel and fully enjoy the nature and socio-culture that has been created by the village. In relation to that, the objectives of this community service activities are (1) Development of educational tourism that is community-based and sustainable, (2) Providing benefits to the community, which can improve community income, (3) Maintaining the sustainability of Olean Village and to avoid the conversion of land uncontrollable.

Keywords: PKM, Educational Tourism Village, Olean Village, Hydroponics

\section{PENDAHULUAN}

Wisata pendidikan, bisa juga disebut sebagai anjangkarya adalah suatu kegiatan atau perjalanan yang dilakukan untuk rekreasi atau liburan dan juga terdapat aktivitas edukasi atau pendidikan didalamnya. Ada banyak kegiatan wisata edukasi yang bisa di lakukan khususnya bagi anak-anak yang masih membutuh pembelajaran akan dunia luar.

Sedangkan penjelasan secara mendalam Wisata Edukasi adalah suatu perjalanan wisata yang memiliki nilai tambah edukasi, tidak sekedar berwisata, tetapi juga memiliki tujuan untuk menambah nilai-nilai edukasi atau pendidikan bagi wisatawan. Wisata edukasi sebuah kegiatan yang umumnya dilakukan oleh institusi pendidikan, seperti sekolah-sekolah maupun institusi pendidikan lainnnya.

Wisata edukasi atau wisata pendidikan bertujuan untuk meningkatkan kecerdasan dan kreatifitas peserta kegiatan wisata. Biasanya tujuan wisata edukasi adalah tempat-tempat yang memiliki nilai tambah sebagai sebuah area wisata, seperti kawasan perkebunan, kebun binatang, tempat penangkaran hewan langka, pusat-pusat penelitian dan lain sebagainya.

Desa Olean Situbondo terdapat beberapa wisata yang saat ini lagi dikembangkan oleh masyarakat setempat. Desa Olean mempunyai potensi sebagai Desa Wisata Edukasi yang masyarakatnya ingin menonjolkan potensi alam dan adat keseniannya. Motto pariwisata di situbondo "East Slide of Paradise". 


\section{INTEGRITAS : Jurnal Pengabdian}

Vol 3, No 2, Desember 2019

ISSN 2580-7978 (Cetak) ISSN 2615-0794 (Online)

Desa wisata edukasi menawarkan pengalaman baru, hidup menyatu dengan alam pedesaan, menghirup udara segar, jauh dari polusi dan kebisingan, merasakan dan terlibat dalam aktivitas masyarakat setempat, dalam artian bahwa wisatawan tidak hanya melihat begitu saja keindahan alam, tetapi dapat hidup di dalamnya. Wisatawan dapat merasakan dan menikmati secara utuh alam dan sosial budaya di desa tersebut. Cara menggali, memanfaatkan, dan membangun sumber daya lokal yang selama ini kurang mendapat perhatian, mengurangi kebocoran, serta untuk meningkatkan pendapatan berganda masyarakat desa setempat, serta untuk menyeleksi segmen pasar wisatawan yang berorientasi pada budaya dan peduli lingkungan.

Masyarakat Desa Olean berusaha untuk mengangkat Situbondo dengan Desa Wisatanya, dan juga aktif dalam kegiatan kesenian adat yang ada. Dalam hal ini terbentuk juga "Kelompok Sadar Wisata" Desa Olean yang siap membantu dalam perkembangan wisata diwilayah tersebut. Berdasarkan latar belakang tersebut, Pengabdian ini mengangkat judul : “Pengembangan Desa Olean Sebagai Desa Wisata Edukasi Menuju Wisata Rakyat Berkelanjutan Di Kabupaten Situbondo (Wisata Edukasi Hidroponik Olean)".

\section{METODE PELAKSANAAN}

\section{Analisis Daya Tarik Obyek Wisata}

Analisis yang dilakukan meliputi (1) analisis kondisi lingkungan; (2) analisis kemudahan akses obyek wisata. Analisis lapang menghasilkan beberapa temuan sebagai berikut :

a) Lokasi tempat wisata masih belum banyak dikenal oleh masyarakat Kota Situbondo, Desa Olean berada di letak sebelah utara kota Situbondo dimana masyarakat hanya melewati tempat tersebut dikarenakan ada tempat wisata yang lebih besar di bandingkan di Desa Olean sendiri. Padahal di Desa Olean ada beberapa tempat wisata : Kampung Hidroponik, Kereta Uap, Karang Kenik 26 KK, Wisata Edukasi Berkebun, Tanggul Angin. Pengabdian ini di fokuskan Kampung Hidroponik. 


\section{INTEGRITAS : Jurnal Pengabdian}

Vol 3, No 2, Desember 2019

ISSN 2580-7978 (Cetak) ISSN 2615-0794 (Online)

b) Kemudahan akses gampang untuk dicari, akan tetapi belum banyak dikenal oleh masyarakat lainnya, terutama masyarakat situbondo itu sendiri.

\section{Analisis Pendukung Wisata}

Analisis lapang di lokasi wisata menunjukkan bahwa belum ada prasarana yang memadai dan nyaman bagi wisatawan. Dalam hal ini fasilitas masih kurang layak untuk obyek wisata.

\section{Analisis Masyarakat}

Pada analisis ini masyarakat belum terlalu sadar dan tidak terlalu banyak mendukung perkembangan wisata yang ada di wilayah tersebut. Warga perlu membenahi wisata tersebut agar lebih meluas dan banyak di kenal masyarakat situbondo dan menjadi pilihan untuk wisatawan luar untuk berkunjung kelokasi tersebut.

\section{HASIL YANG DICAPAI}

Analisis lapangan menghasilkan beberapa program yang dilakukan oleh Tim Program Kemitraan Masyarakat (PKM) Universitas Abdurachman Saleh Situbondo menghasilkan antara lain:

1. Pembuatan penunjuk arah menuju beberapa wisata yang ada di wilayah olean, agar mempermudah pengunjung ke lokasi tersebut.

2. Tanaman yang digunakan semuanya tanaman hidroponik yang tidak menggunakan tanah, akan tetapi menggunakan beberapa vitamin tanaman dan pipa untuk mengalirnya air.

3. Adanya kegiatan-kegiatan untuk edukasi/pembelajaran anak-anak sekolah bahkan untuk kelompok-kelompok yang ingin mengetahui cara menanam dengan hidroponik.

4. Sosialisasi pentingnya wisata edukasi yang di selenggarakan oleh POKDARWIS Olean kepada masyarakat sekitar. 


\section{INTEGRITAS : Jurnal Pengabdian}

Vol 3, No 2, Desember 2019

ISSN 2580-7978 (Cetak) ISSN 2615-0794 (Online)

Berikut adalah hasil yang telah dilaksanakan Program Kemitraan Masyarakat dalam rangka peningkatan potensi Wisata Edukasi Hidroponik Olean.

Pembuatan petunjuk arah yang dilakukan dengan membuat model kayu agar menarik dilihat oleh pengunjung yang datang ke wilayah Desa Olean.

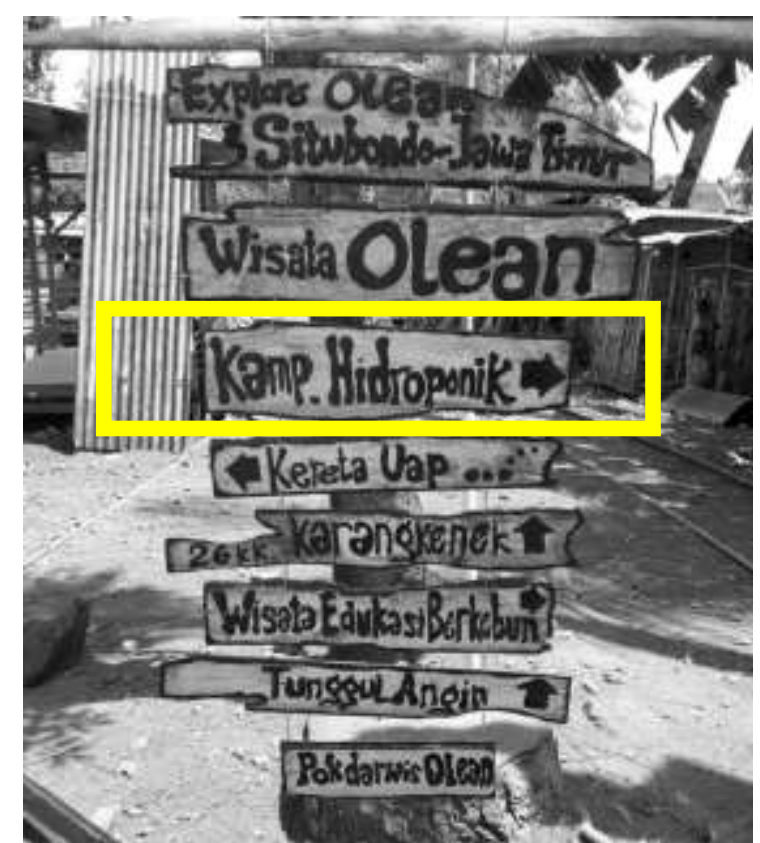

Gambar 1. Petunjuk arah menujuh beberapa wisata (Kamp. Hidroponik)

Wisata Edukasi Hidroponik olean dibuat unik agar para pengunjungan betah berlama-lama di lokasi tersebut dan banyak macam tanaman yang bisa dilihat, serta tanaman tersebut bisa dipanen seperti buah dan sayuran. 


\section{INTEGRITAS : Jurnal Pengabdian}

Vol 3, No 2, Desember 2019
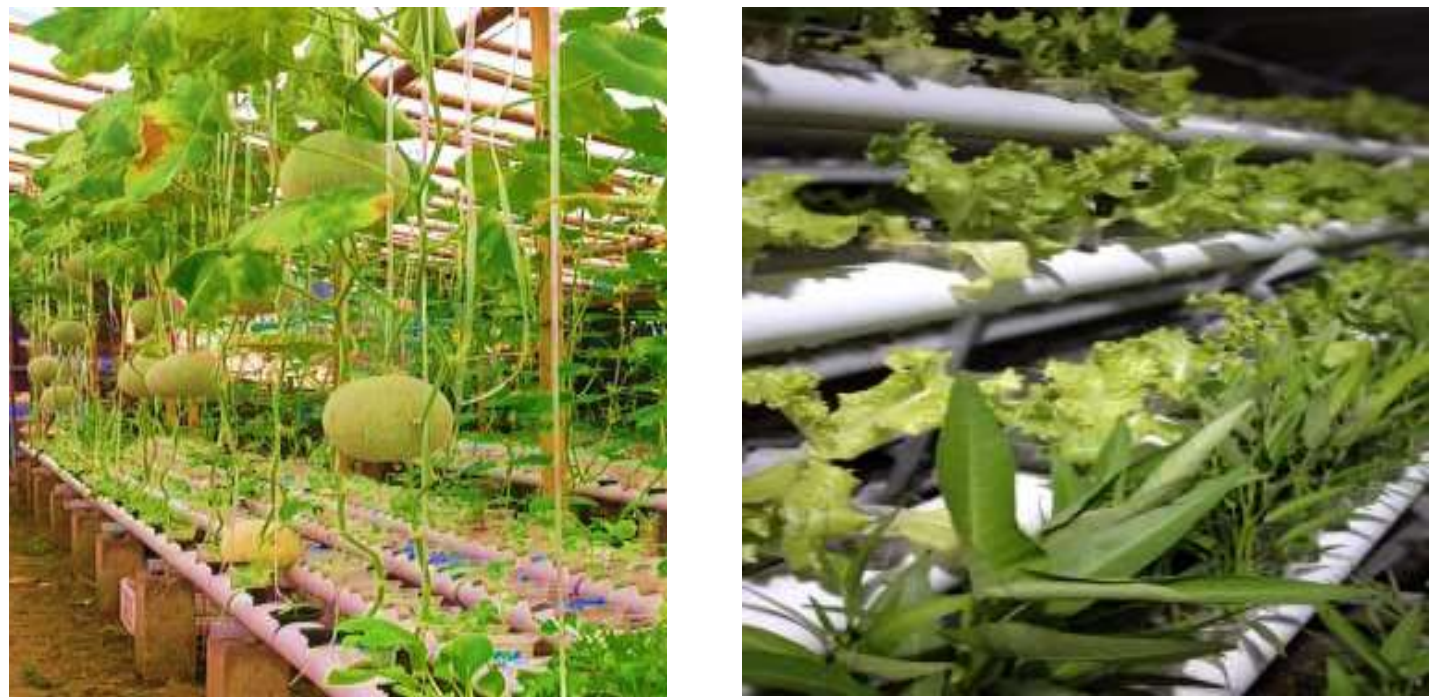

Gambar 2. Tanaman Hidroponik buah-buahan dan sayuran

Adapun kegiatan pembelajaran yang sering dilakukan oleh pengelolah POKDARWIS dan juga masyarakat desa, bekerjasama dengan sekolah-sekolah dan kelompok-kelompok yang ingin mengetahui budidaya tanaman Hidroponik agar bisa menanam dengan cara praktis dan tidak makan tempat untuk yang tidak mempunyai lahan untuk bercocok tanam.

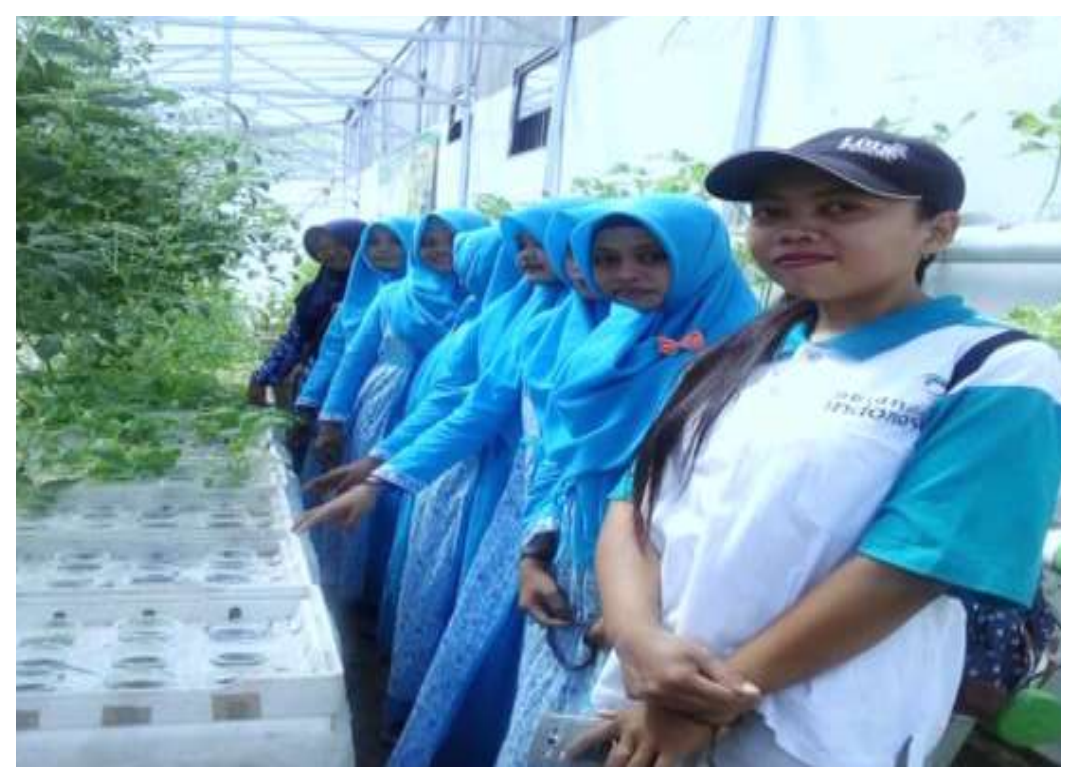

Gambar 3. Kunjungan Ibu-ibu PKK 


\section{INTEGRITAS : Jurnal Pengabdian}

Vol 3, No 2, Desember 2019

ISSN 2580-7978 (Cetak) ISSN 2615-0794 (Online)

Sosialisasi akan terus dilakukan untuk perkembangan Wisata Edukasi Hidroponik Olean dengan cara berceramah dan berdiskusi bersama warga Desa Olean untuk kemajuan bersama. Dengan adanya Desa Wisata Edukasi Hidroponik Olean bisa meningkatkan pendapatan Desa Olean dan juga masyarakat sekitarnya.

\section{KESIMPULAN}

Setelah kegiatan Program Kemitraan Masyarakat di Desa Olean sebagai Desa Wisata Edukasi Khususnya Wisata Hidroponik Olean, bisa memaksimalkan potensi wisata yang ada. Dengan adanya program PKM dan bekerjasama dengan POKDARWIS Desa Olean agar masyarakat bisa berkunjung dengan mudah dan dapat melestarikan tanaman hidroponik di wilayah Situbondo.

\section{SARAN}

Saran setelah PKM ini selesai dilaksanakan adalah :

1. Menjaga melestarikan tempat Wisata Edukasi Hidroponik agar bisa menarik pengunjung lebih banyak lagi.

2. POKDARWIS menginformasikan kepada masyarakat kota dan mempopulerkan tempat dengan dokumentasi yang menarik.

3. Tempat selalu di perbaharui agar para pengunjung tidak bosan untuk selalu datang ke tempat lokasi.

\section{DAFTAR PUSTAKA}

Ardika, I Wayan, 2003. Pariwisata Budaya Berkelanjutan. Denpasar: Program Studi Magister KajianPariwisata, Universitas Udayana.

Anonim, 2005, Inventarisasi Topik Program Pengabdian Kepada Masyarakat, Yogyakarta: LPM UNY.

Suherlan, A. (2016). Analisis Karakteristik, Perilaku, dan Motivasi Perjalanan Wisatawan Asal Sulawesi Utara ke Jakarta. Esensi: Jurnal Bisnis dan Manajemen, 4(3), 1-1.

Suyuti, 2018, Wawancara dengan Kepala Desa Sitiluhur Kecamatan Gembong Kab Pati.

Widodo Suwarno DKK, 2018, Panduan Pengabdian Kepada Masyarakat, Semarang LPPM

\section{UPGRIS}

